Int. J. Dev. Biol. 51: 415-423 (2007)

doi: $10.1387 / \mathrm{ijdb} .062263 \mathrm{sm}$

Short Communication

\title{
Key apoptosis regulating proteins are down-regulated during postnatal tissue development
}

\author{
SHANE D. MADDEN, MARYANNE DONOVAN and THOMAS G. COTTER* \\ Cell Development and Disease Laboratory, Department of Biochemistry, Biosciences Institute, University College, Cork, Ireland
}

\begin{abstract}
The intrinsic apoptotic pathway is essential for murine development. We have previously shown that key mediators of this pathway, such as Bim, Apaf-1 and caspase-3, are down-regulated during the postnatal development of the retina. In this study, we demonstrate that this expression pattern is a feature of other distinct tissues such as the brain, heart and skeletal muscle. Caspase- 9 expression is also examined and is shown to follow a different pattern in each tissue. Interestingly, we show that peripheral cells of the internal granular layer of the cerebellum do not down-regulate the intrinsic apoptotic pathway proteins Bim, Apaf-1 or caspase3. Furthermore, Bim expression is also detectable in the brain stem and the CA3 region of the hippocampus in the adult cerebrum. Finally, we demonstrate that the incidence of TUNEL positive cells in the selected tissues decreases during postnatal development in correlation with the general down-regulation of key apoptotic pathway proteins. In contrast, we also demonstrate that apoptosis persists in the adult thymus and that this tissue continues to express Bim, Apaf1 and caspase- 3 at the same levels as the neonate. In summary, this study shows that a selection of post-mitotic tissues down-regulate key apoptotic proteins, in contrast to the thymus, which requires apoptosis for normal function in early adulthood.
\end{abstract}

KEY WORDS: Bim, Apaf-1, caspase-3, caspase-9, postnatal development

The deregulation of apoptosis is evident in pathological conditions such as cancer and neurodegenerative disorders (Danial and Korsmeyer, 2004). Apoptosis is orchestrated by a family of cysteine proteases (caspases), which are expressed as inactive zymogens. During apoptosis, caspases are proteolytically cleaved at specific aspartate residues between large and small subunits. The cleaved subunits re-associate and form enzymatically active monomers (Riedl and Shi, 2004). Two major caspase pathways have been described. The extrinsic pathway is initiated through the binding of ligands to cell surface receptors, which recruit and activate caspase 8 , which activates the key executioner caspase3. The intrinsic pathway is initiated by cytochrome $c$ release from the mitochondrion. Cytochrome $c$ causes the oligomerisation of Apoptotic Activating Factor 1 (Apaf-1), which recruits and activates caspase- 9 , which also activates the executioner caspase3 (Fuentes-Prior and Salvesen, 2004). Cytochrome $c$ release is regulated by the $\mathrm{Bcl}-2$ protein family. Pro-apoptotic Bcl-2 family members Bax and/or Bak oligomerise and form openings in outer membrane of the mitochondrion in response to the binding of small BH3-only proteins known as activators, such as Bid and Bim (Certo et al., 2006).

The intrinsic apoptotic pathway is vital for the correct develop- ment of the mouse. This is best illustrated by the caspase-3, -9 and Apaf- 1 knock-out models, all of which exhibit perinatal lethality, enlarged brains and craniofacial abnormalities (Kuida et al., 1996, Cecconi et al., 1998, Hakem et al., 1998, Kuida et al., 1998 and Yoshida etal., 1998). Our group has previously shown that as the murine retina continues to develop postnatally, it downregulates several key proteins of the intrinsic apoptotic pathway as well as pro-apoptotic members of the Bcl-2 family. Bim is the first $\mathrm{Bcl}-2$ family member to be down-regulated and its downregulation correlates with a marked desensitisation of the retina to apoptotic insults. It has been postulated that this may be a defence mechanism employed by the retina to protect against the loss of irreplaceable cells (Donovan and Cotter, 2002 and Donovan et al., 2006). In this study we examined whether the postnatal down-regulation of intrinsic apoptotic pathway proteins also occurred in other distinct tissues, namely the brain, skeletal muscle and the heart. We also examined the expression of each protein immunohistochemically, in order to determine the regions of each tissue that express the intrinsic apoptotic pathway proteins. Our

Abbreviations used in this paper: Apaf, apoptotic activating factor; ER, endoplasmic reticulum; IGL, internal granular layer

\footnotetext{
*Address correspondence to: Thomas G. Cotter. Cell Development and Disease Laboratory, Department of Biochemistry, Biosciences Institute, University College, Cork, Ireland. Fax: +353-21-490-1382. e-mail: t.cotter@ucc.ie
} 
results demonstrate that Bim, Apaf- 1 and caspase- 3 are downregulated in the neocortex of the adult brain and in adult skeletal muscle and heart, whereas, the expression of all three proteins is sustained in the IGL of the adult cerebellum and in the adult thymus.

\section{The postnatal developmental expression pattern of intrinsic apoptotic pathway proteins}

To determine whether the intrinsic apoptotic pathway is globally down-regulated in adult tissues, we investigated the expres-

A

$$
\text { Bim }
$$
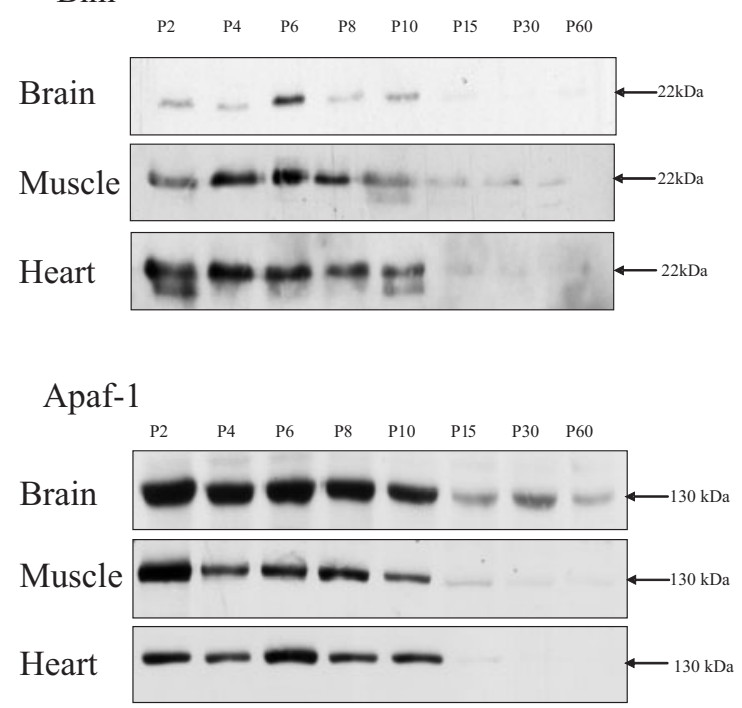

Caspase-3

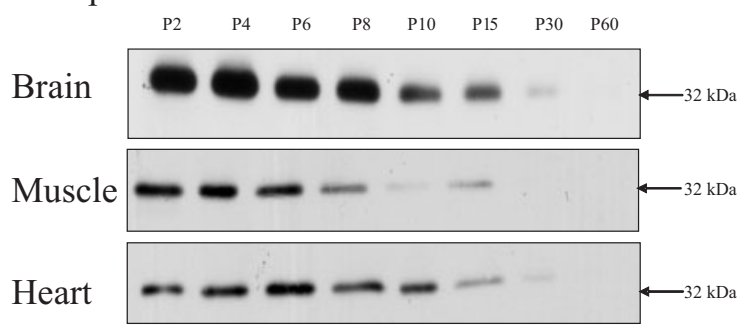

Caspase-9

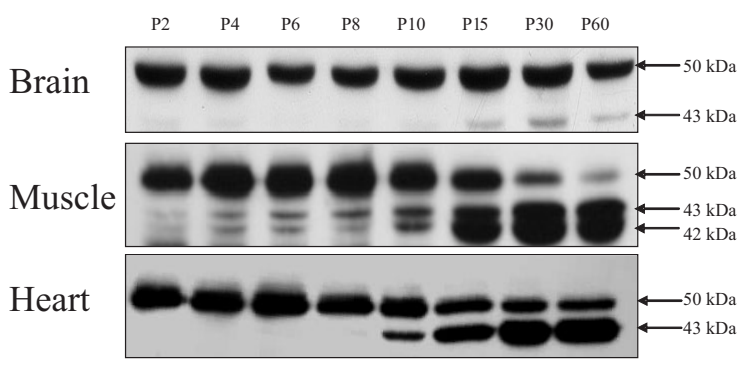

sion of key mediators of this pathway in the brain, heart and skeletal muscle tissue and compared their expression between neonatal and adult mice. As Bim was shown to be particularly potent at inducing cytochrome $c$ release, the apical event of the intrinsic apoptotic pathway (Certo et al., 2006) and we have previously shown that it is down-regulated in the adult retina (Donovan et al., 2006), we decided to examine its expression in brain, skeletal muscle and heart during postnatal development. Its expression levels peaked at P6 in the brain and in skeletal muscle and at P4 in the heart (Fig. 1A). It was barely detectable after P10 in all of the tissues examined.

We investigated the postnatal expression patterns of Apaf-1 and caspase-3, because they play an essential role in both murine development and the intrinsic apoptotic pathway (Kuida et al., 1996, Cecconi et al., 1998, Yoshida et al., 1998 and Slee et al., 2001). In a similar manner to Bim, both proteins were strongly down-regulated before P15 in each tissue (Fig. 1A). All three proteins were down-regulated between P10 and P15 in each tissue, with the exception of caspase-3, which was down-regulated in brain, between $\mathrm{P} 8$ and $\mathrm{P} 10$ and in muscle between $\mathrm{P} 6$ and P8. The postnatal developmental expression pattern of all three proteins was strikingly similar to what we have previously observed in the postnatal retina (Donovan and Cotter, 2002 and Donovan et al., 2006). Our work is supported by other groups that have examined Apaf- 1 and caspase- 3 expression in brain and skeletal muscle in humans and in various strains of rats and mice (Burgess etal., 1999, Yakovlev etal., 2001, Ruest etal., 2002 and Stoka et al., 2006). However, here we have also extended our study to the heart, thereby demonstrating that the down-regulation of key intrinsic apoptotic pathway mediators occurs in three distinct tissues during postnatal development and that this correlates with a significant reduction in TUNEL positive cells in the adult (Fig. 1B).

The postnatal developmental expression pattern of caspase9 was quite different from that of Apaf- 1 and caspase- 3 and also varied considerably between each tissue (Fig. 1A). Caspase-9 was markedly down-regulated between P15 and P30 in skeletal muscle. Its expression was also decreased in the heart between $\mathrm{P} 10$ and $\mathrm{P} 15$, but unlike skeletal muscle, the adult heart continued

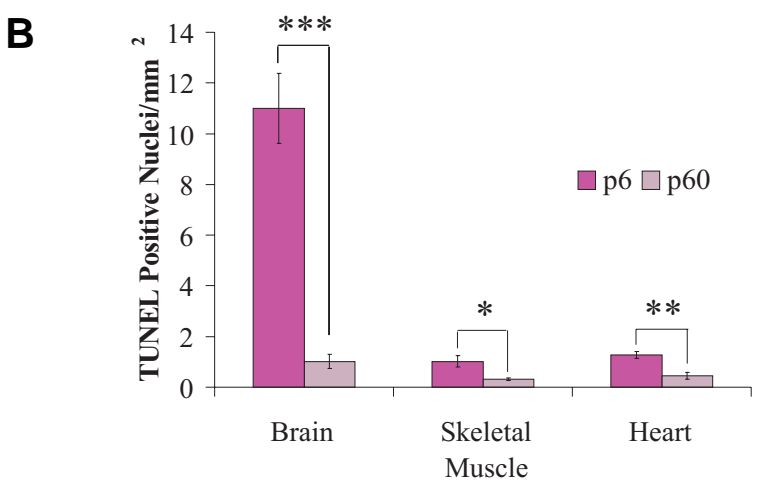

Fig. 1. The postnatal developmental expression pattern of intrinsic apoptotic pathway proteins. (A) Immunoblots of brain, skeletal muscle and heart of mice aged between postnatal day (P) 2 and 60 are depicted. Immunoblots were probed with anti-Bim, anti-Apaf-1, anti-caspase-3 and anticaspase-9 antibodies as indicated. Equal loading was confirmed by staining with Ponceau $S$. The immunoblots depicted are representative of those of three different mice for each tissue for each age group. (B) The TUNEL positive nuclei of each tissue for both age groups were quantified and normalised with respect to the area of each section. Each point represents the mean of six mice $+/$ - standard error. The Student $t$-Test was performed to calculate the significance of the difference between neonate and adult counts for each tissue; ${ }^{*}, p<0.05, * *, p<0.01$ and ${ }^{* * *}, p<0.001$. 
to express caspase- 9 at relatively high levels. Its expression remained unchanged in the brain during postnatal development; this may be due to the presence of glial and other non-neuronal cells in the adult brain. The significance of the sustained expression of caspase- 9 in adult brain and heart is unclear, as its activator and its executioner, Apaf-1 and caspase-3 respectively, were markedly down-regulated by P60. However, caspase- 9 can also be activated in the absence of Apaf-1 and of cytochrome $c$ release, through the endoplasmic reticulum (ER) stress pathway (Rao et al., 2001 and Morishima et al., 2002, respectively). As ER stress has been implicated in a number of neurodegenerative diseases and in heart disease, it is possible that sustained caspase- 9 expression in the adult brain and heart sensitises these tissues to ER stress (Xu, et al., 2005). Caspase-9 has also been shown have a role in haematopoiesis in addition to its role in apoptosis (Zermati et al., 2001, De Botton et al., 2002 and Sordet et al., 2002). The possibility that caspase-9 may have an alternative function in adult brain and heart is intriguing and merits further investigation. Interestingly, our anti-caspase-9 antibody also cross-reacted with a $43 \mathrm{kDa}$ protein, which was dramatically up-regulated during the postnatal development of both heart and muscle. As this protein was larger than any previously described processed fragment of mouse caspase-9, we are currently investigating its identity.

We wished to examine whether the down-regulation of caspase- 3 and -9 occurred as a result of proteolytical cleavage or at the transcriptional level. To this end, we compared the neonatal expression of caspases- 3 and -9 mRNA to that of the adult by RT-PCR. We found that the postnatal developmental expression pattern of caspase-3 mRNA correlated with that of caspase- 3 protein in all three tissues, where caspase- 3 message was down-regulated markedly in all three adult tissues (Fig. 2), indicating that the down-regulation of caspase-3 occurred at the mRNA level, rather than at the protein level. This was further supported by the non-detection of processed caspase- 3 fragments by western blot. Interestingly, Ruest and colleagues previously demonstrated that the down-regulation of caspase-3 in rat skeletal muscle occurred at the protein level, rather than at the mRNA level (Ruest et al., 2002). These contrasting results suggest that the regulation of caspase- 3 expression is distinct for different species. The postnatal developmental expression pattern of caspase- 9 mRNA in the brain and skeletal muscle correlated with that of caspase- 9 protein in both tissues, where caspase- 9 mRNA and protein levels remained the same in the adult brain and both caspase- 9 mRNA and protein levels decreased in adult skeletal muscle. However, the developmental expression pattern of caspase- 9 mRNA did not correlate with that of caspase- 9 protein in the heart. While caspase- 9 protein levels decreased in the adult, mRNA levels remained the same throughout heart development. Therefore, the decreased caspase- 9 expression may be the result of novel proteolytical cleavage of caspase- 9 , supported by the detection of the $43 \mathrm{kDa}$ protein in the adult heart by the anticaspase- 9 antibody. Indeed, as the $43 \mathrm{kDa}$ protein was also detectable in brain and skeletal muscle, we cannot rule out the possibility that a novel processing of caspase- 9 may also occur in both these tissues. However, as there is no concomitant increase in TUNEL positive cells (in fact, the opposite is observed) or in active caspase- 3 cleaved products, it appears that any developmental proteolytical cleavage of caspase- 9 in adult brain, skeletal muscle or heart tissue is not pro-apoptotic in nature.

\section{An immunohistochemical analysis of intrinsic apoptotic path- way protein expression in neonatal and adult tissue}

We have demonstrated a marked down-regulation of Apaf-1, Bim and caspase-3 in distinct tissue types during postnatal development by western blot. While western blot analysis is valid for the measurement of protein expression in the whole tissue, it may preclude detection of the proteins if their expression is sustained in distinct tissue areas or in specific cell-types in the adult tissue. We therefore, also used immunohistochemistry to examine the postnatal developmental expression pattern of Bim, Apaf-1 and caspase-3 in brain, muscle and heart. We demonstrate that Bim, Apaf-1 and caspase-3 all exhibited continuous cytosolic staining throughout neonatal heart in a similar pattern to myosin heavy chain, indicating that neonatal cardiomyocytes expressed all three apoptotic mediators (Fig. 3). In addition, we also demonstrated the absence of myosin heavy chain in the cells of blood vessels, as expected, whereas these cells did stain positively for all three apoptotic mediators, indicating that Bim, Apaf- 1 and caspase-3 expression in the postnatal developing heart is not limited to cardiomyocytes. We also show that Bim, Apaf-1 and caspase-3 were down-regulated throughout the adult heart in correlation with our western blot results, with no apparent retention by any discreet area or specific cell type.

Bim and Apaf-1 expression in neonatal skeletal muscle exhibited a similar pattern to that of myosin heavy chain, indicating that neonatal myofibres expressed both apoptotic mediators (Fig. 3). We could not detect the expression of either protein in adult skeletal muscle in correlation with our western blot results, indicating that neither protein was retained by any discreet area or specific cell type. Interestingly, the expression pattern of caspase3 in neonatal skeletal muscle exhibited a different pattern to that of Bim and Apaf-1 and, indeed, myosin heavy chain. Caspase-3 immunostaining was punctuate and seemed to localise around nuclei, suggesting that caspase- 3 is localised in the nucleus of neonatal skeletal muscle, which has been previously observed in

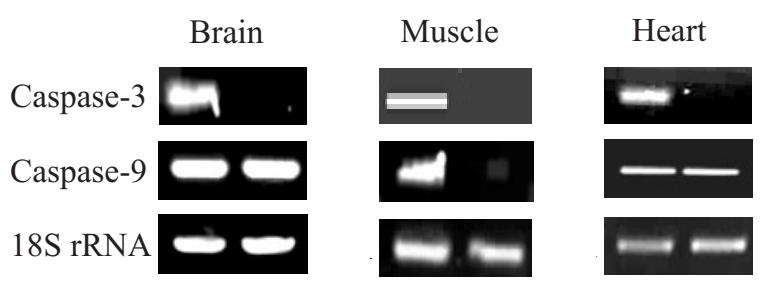

Fig. 2. The expression of caspase-3 and -9 mRNA in neonatal (P6, left colums) and adult (P60 right columns) tissue. RT-PCR analysis was performed to detect the expression levels of caspase-3 and -9 in tissue of the neonate and the adult. Total RNA was purified from brain, skeletal muscle and heart taken from P6 and P60 mice and converted to CDNA by reverse transcription. The subsequent $C D N A$ was amplified using oligonucleotide primers specific for caspase-3, -9 and 18S rRNA. The PCR products were analysed by electrophoresis through a 1.5\% agarose gel and visualised by ethidium bromide staining. $18 S \mathrm{~S} R N A$ expression was used as a loading control. 


\section{Heart}

P6

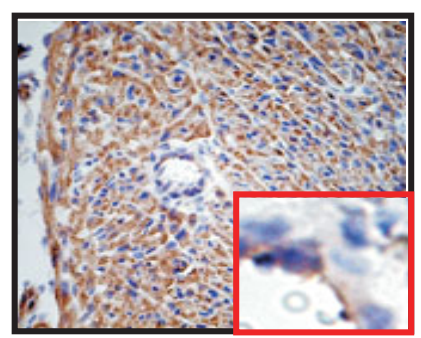

Bim

Apaf-1
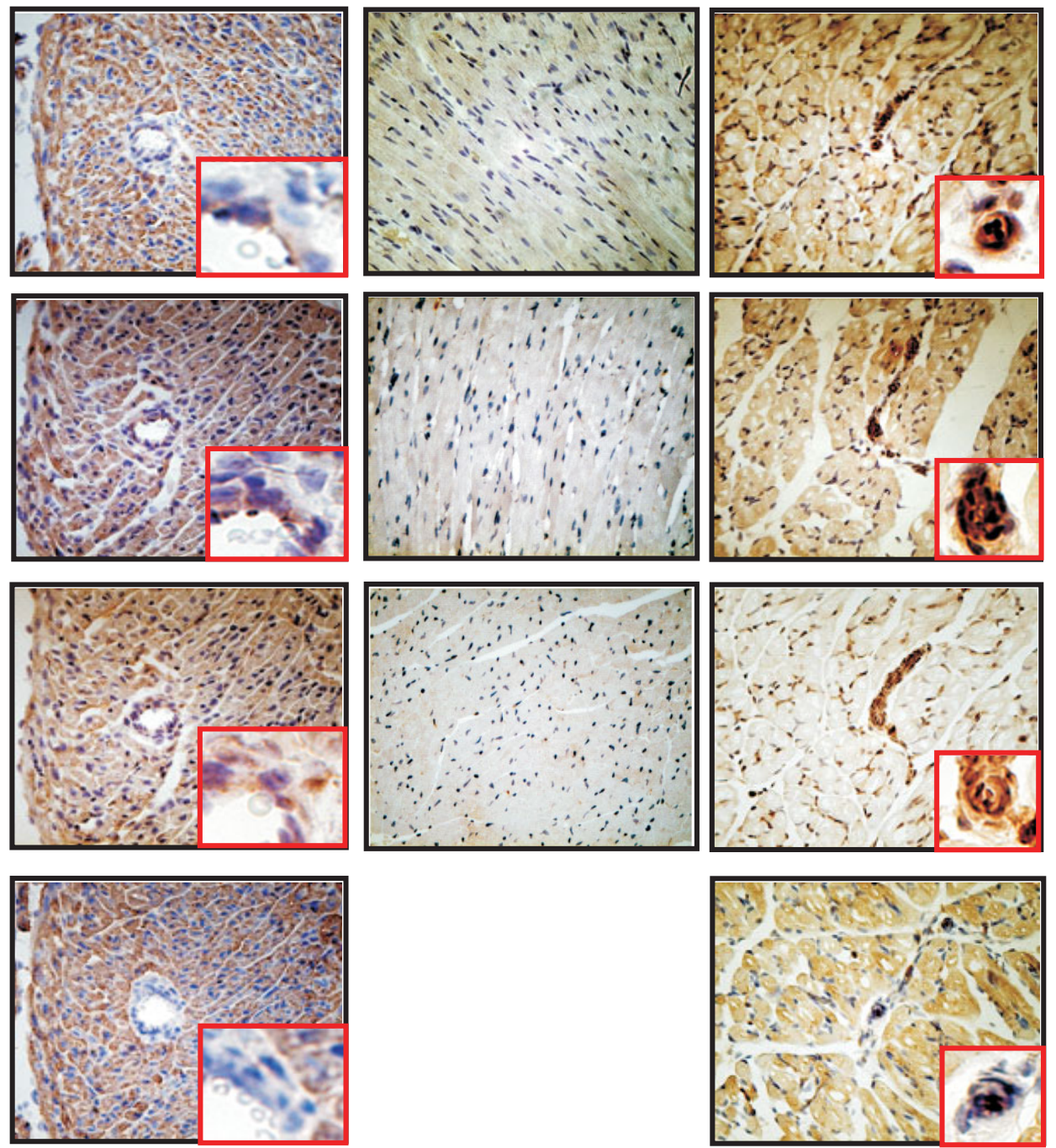

Skeletal Muscle P6 P60
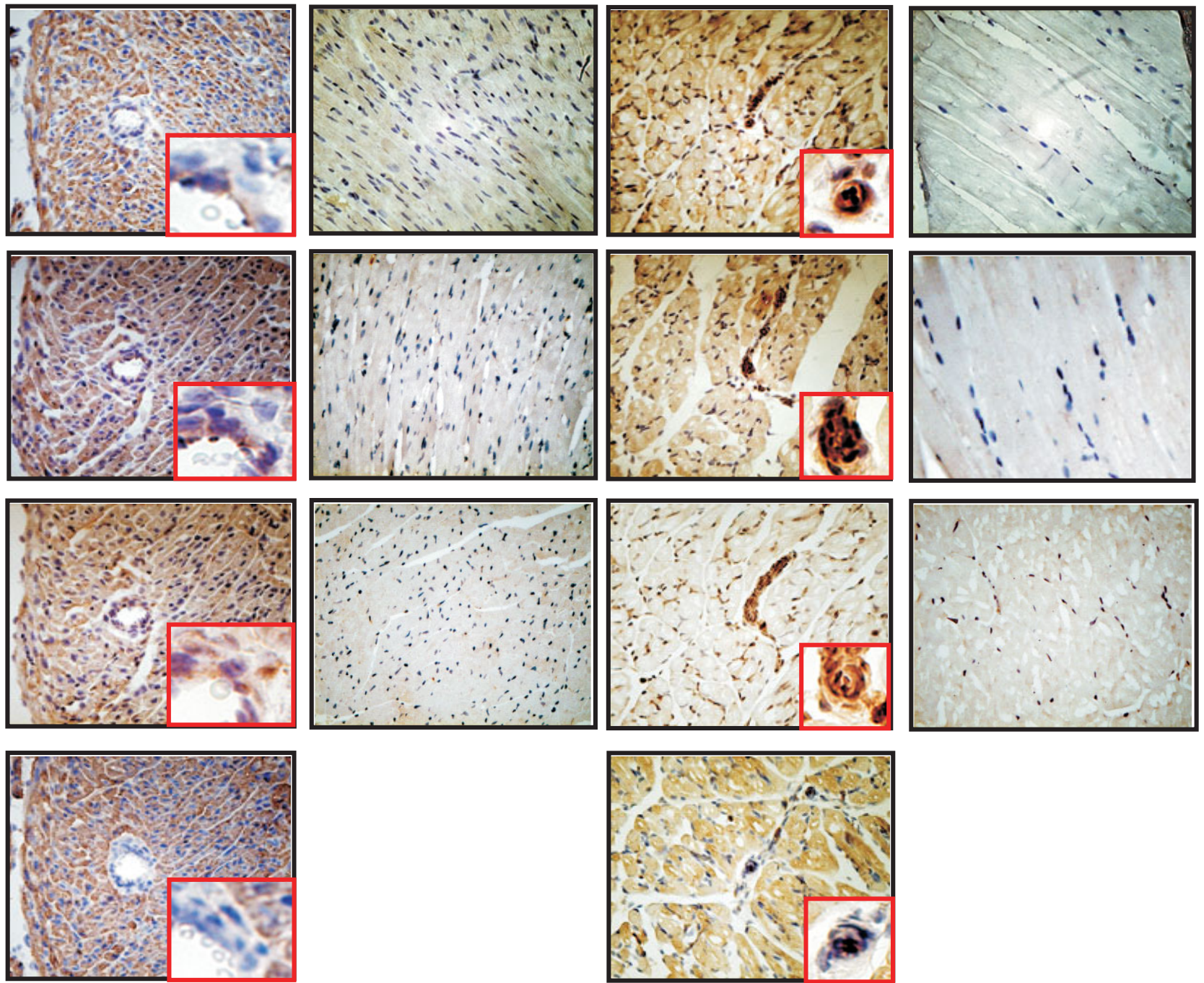

Fig. 3. Immunohistochemical analysis of intrinsic apoptotic pathway protein expression in neonatal and adult heart and skeletal muscle tissue. Longitudinal sections of thigh muscle and heart taken from P6 and P60 mice were probed with antibodies directed against Bim, Apaf-1 and caspase-3 and, where positive, an antibody that detects cardiac and skeletal muscle heavy chain myosin, as indicated. As neonatal sections of both heart and skeletal muscle were positive for each apoptotic protein, serial sections were probed for Bim, Apaf-1, caspase-3 and myosin heavy chain using blood vessels for orientation. All images were taken at $40 X$ and the inserts depict expanded images of the centre blood vessels. Heart and skeletal muscle tissue was taken from three different mice at each age and at least five fields of each tissue were examined at $40 X$ for positive staining; the depicted images are representative of all examined fields.

other systems, (Mandal et al., 1999, Noyan-Ashraf et al., 2005, Ramuz et al., 2003). Alternatively, the caspase-3 expression pattern is also suggestive of specific caspase- 3 expression by differentiating myoblasts in the developing muscle, as caspase3 activity is required for myoblast differentiation (Fernando et al., 2002). In addition, we demonstrated that caspase-3 was downregulated in the adult tissue in correlation with our western blot results.

Bim, Apaf-1 and caspase-3 were detectable in the neocortex and the developing cerebellum of the neonatal brain (Fig. 4A). The staining pattern of all three proteins in the neocortex strongly resembled that of NeuN, a neuron-specific marker, in serial sections, suggesting that neonatal neocortical neurons express all three apoptotic mediators. In support of this, higher magnification revealed that Bim, Apaf- 1 and caspase- 3 positive cells exhibited similar morphology to that of NeuN positive neurons. However, we were also able to detect caspase-3 in cellular processes outside of cell bodies in a similar pattern to that of glial fibrillary acidic protein (GFAP), a glial cell marker, suggesting that caspase-3 was also expressed by neonatal glial cells. We could not detect the expression of Bim, Apaf-1 or caspase-3 in the neocortex of adult mice in correlation with our western blot results, 
which demonstrated the down-regulation of all three apoptotic mediators in the whole brain. We also examined the expression patterns of all three mediators in the neonatal cerebellum (Fig. 4B). Apaf-1 and caspase-3 exhibited similar staining patterns and were detectable in the external granular layer (EGL), the molecular layer and the IGL, whereas Bim was only detectable in the EGL and on the external margin of the IGL. Detection of all three mediators in both granular layers in conjunction with NeuN staining suggests that neonatal granule neurons express all three apoptotic mediators; however, the positive staining of both layers by GFAP suggests that cerebellar glial cells may also express

A

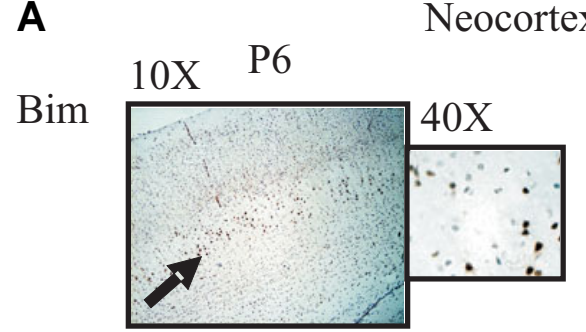

A-1

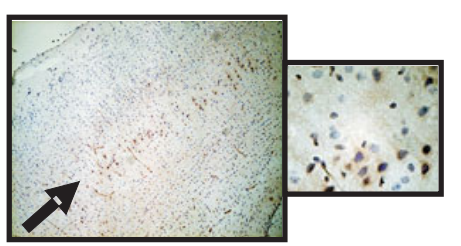

C-3

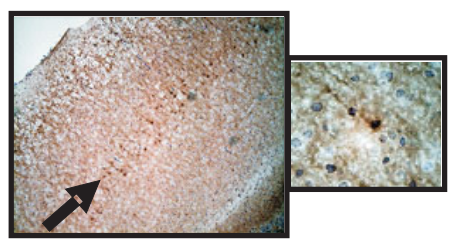

NeuN

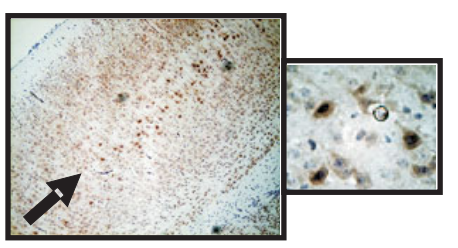

GFAP

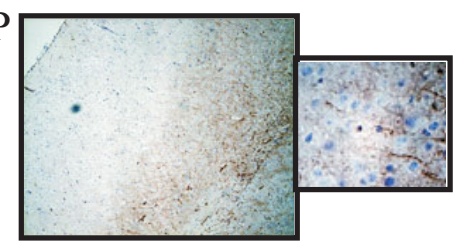

Bim, Apaf-1 and caspase-3. Surprisingly, we were also able to detect Bim, Apaf-1 and caspase-3 in the IGL of the adult cerebellum. We specifically detected each protein in a layer of cells on the external margin of the IGL. Given that Purkinje cells are present in this region of the cerebellum, we stained serial sections with the Purkinje-specific marker, calbindin, along with NeuN, which does not detect Purkinje cells (Mullen et al., 1992) and GFAP. Bim, Apaf-1 and caspase-3 positive cells all exhibited a similar morphology to that of the Purkinje cell. Furthermore, the absence of Bim, Apaf- 1 and caspase-3 staining in the interior of the IGL, which stains positively for NeuN and GFAP, strongly suggests

B

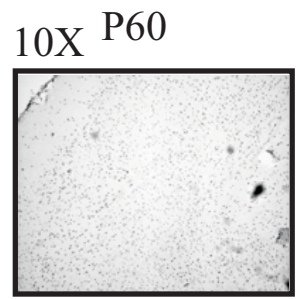

$\operatorname{Bim}$
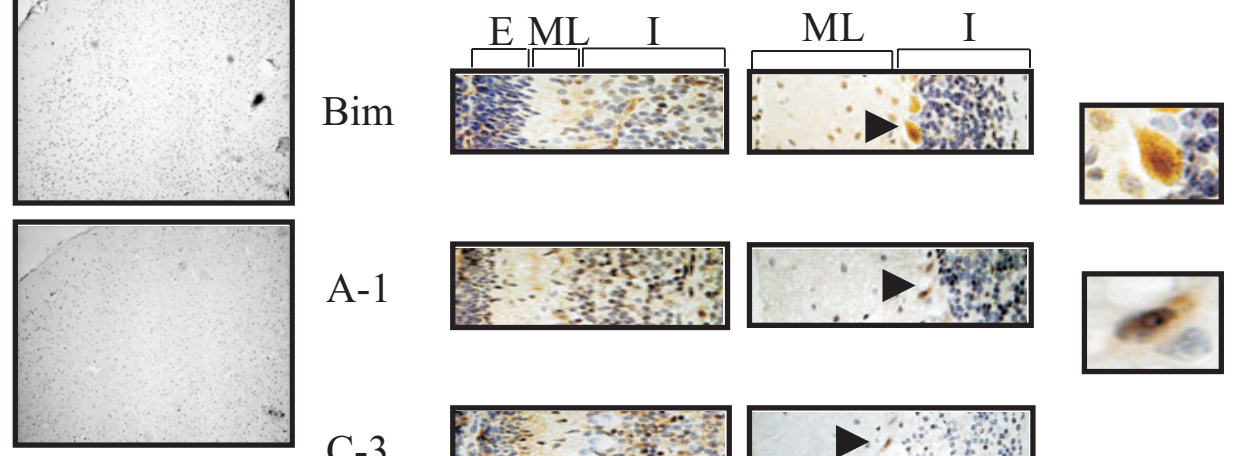

A-1
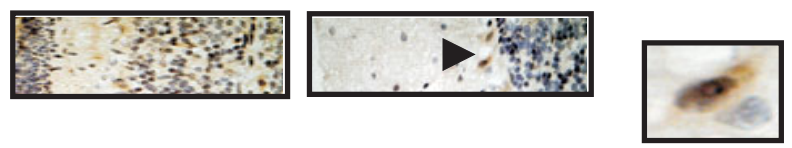

C-3
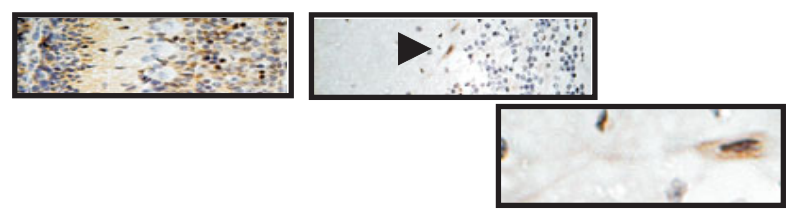

NeuN
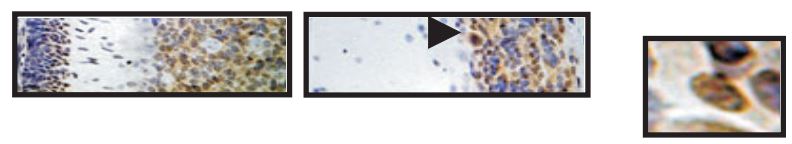

GFAP
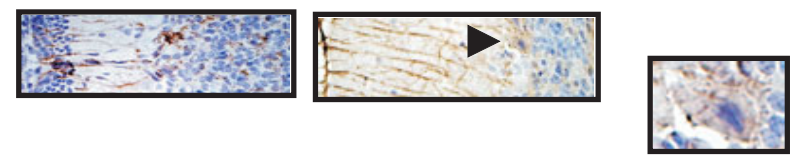

Calbindin

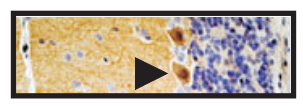

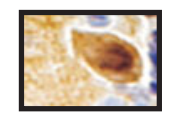

Fig. 4. Immunohistochemical analysis of intrinsic apoptotic pathway protein expression in neonatal and adult brain tissue. The immunostaining of neonatal and adult neocortex and cerebellum for Bim, Apaf-1 and caspase-3 is depicted, as indicated. (A) As neonatal sections of neonatal neocortex were positive for each apoptotic protein, serial sections of the neocortex were probed for Bim, Apaf-1 and caspase-3 followed by the neuron-specific marker NeuN and the glial cell-specific marker GFAP. The positive staining of a particular cortical layer by antibodies directed against the apoptotic proteins, which correlated strongly with NeuN staining is indicated by an arrow. Images were initially taken at 10X, but where positive staining occurred, images were taken of the centre of each 10X field at 40X to demonstrate the morphology of positively stained cells. (B) The immunostaining of neonatal and adult cerebellum is depicted. As both neonatal and adult cerebellum stained positively for Bim, Apaf-1 and caspase-3, serial sections of each age were probed for these apoptotic proteins as well as NeuN and GFAP. Additionally, as the morphology of cells positive for all three apoptotic proteins in the adult cerebellum strongly resembled that of Purkinje cells, the adult cerebellum was additionally probed with the Purkinje cell-specific marker, calbinden. All images were taken at 40X, where positively stained cells of the adult cerebellum indicated by arrow heads were expanded to demonstrate their morphology. Brains were taken from three different mice at each age and the entire neocortex, as well as the entire cerebellum of each brain were examined for positive staining at 10X; the depicted images are representative of all examined fields. Abbreviations: E, external granular layer; ML, molecular layer; I, internal granular layer. 

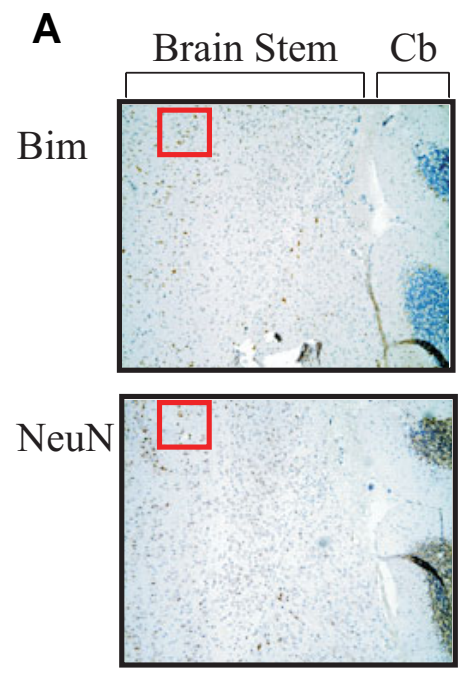

B

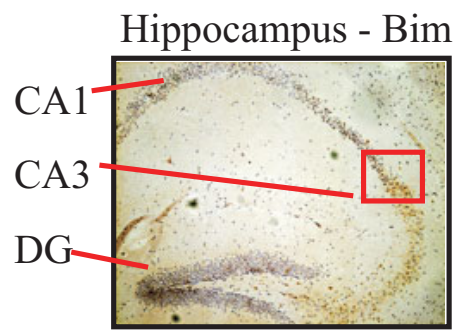

$40 \mathrm{X}$
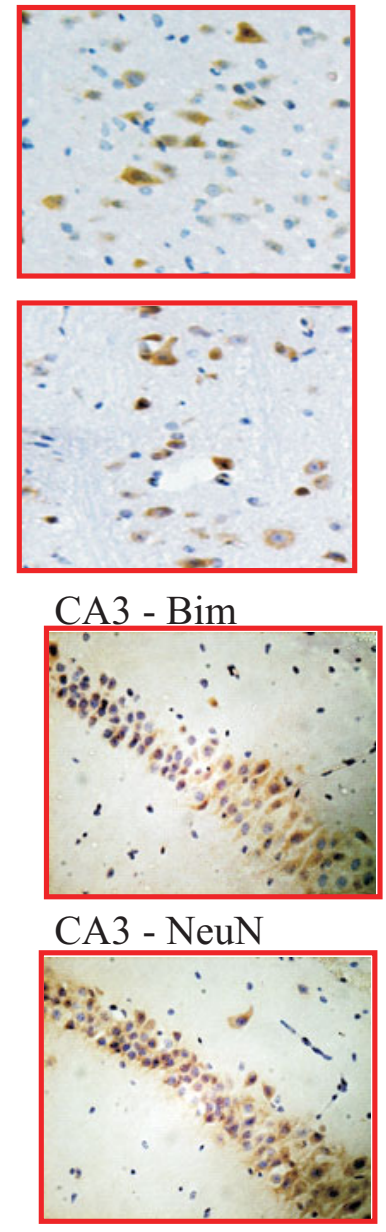

A
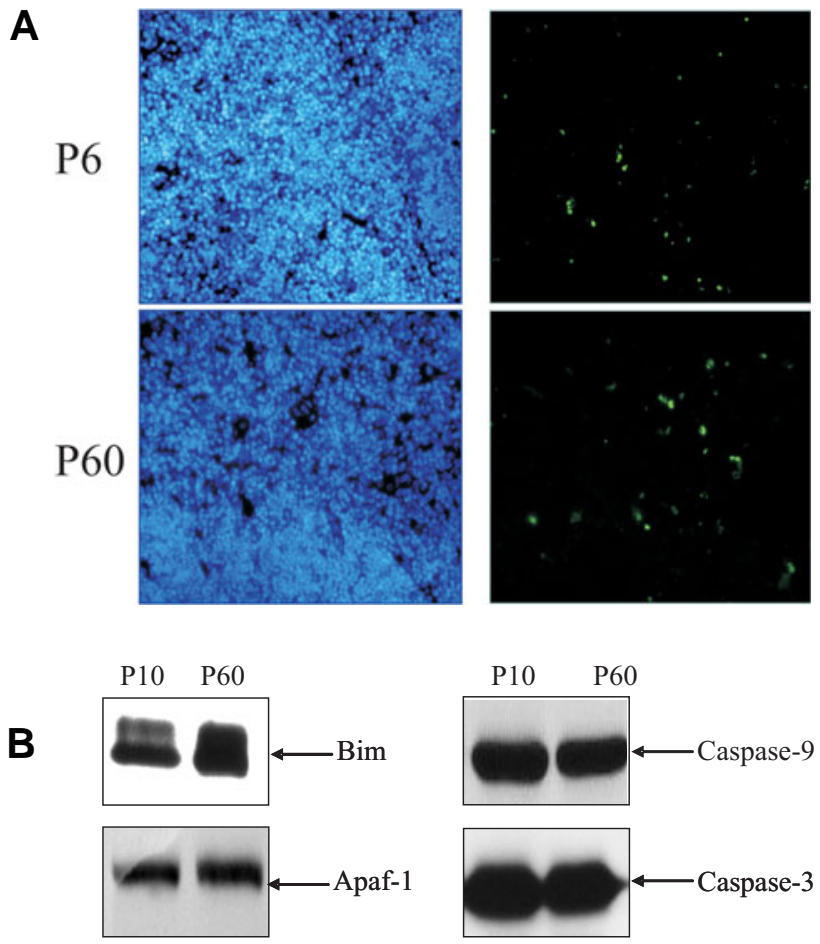

Fig. 5. (Left) Analysis of Bim staining in adult brain stem and hippocampus. Positive Bim staining was also observed in the adult brain stem and hippocampus. (A) Images taken at $10 \mathrm{X}$ of serial sections of brain stem probed with Bim and NeuN using the cerebellum (Cb) for orientation are depicted. The indicated area of each serial section was expanded and depicted on the right in order to demonstrate the morphology of positively stained cells. Brains taken from three different adult mice and at least five 10X fields of the brain stem of each brain were examined for positive staining, where these fields were also examined at $40 X$ to confirm neuronal morphology; the depicted images are representative of all examined fields. (B) Positive Bim staining of the CA3 region of the hippocampus is depicted at 10X. Images taken at 40X of the CA3 region serially stained for Bim and NeuN are also depicted as indicated. The adult CA3 region of three different mice was examined for positive staining at 10X, where the CA3 was also examined at $40 X$ to confirm neuronal morphology; the depicted images are representative of all examined CA3 regions.

Fig. 6. (Right) TUNEL and apoptotic protein expression in the neonatal and adult thymus. (A) Longitudinal sections of thymus taken from P6 and P60 mice are stained with Hoechst 33342 (blue) and TUNEL (green). Thymi were taken from three different mice of each age and at least five fields were examined at 4OX for TUNEL staining; the depicted images are representative of all examined fields. (B) Immunoblots of thymi taken from P10 and P60 mice are depicted. The immunoblots were probed with anti-Bim, anti-Apaf-1, anti-caspase-9 and anti-caspase-3 antibodies as indicated. Equal loading was confirmed using Ponceau S.

that the expression of each protein in the adult cerebellum is Purkinje cell-specific. Two studies published in 2006 reported a susceptibility of cells of the IGL to forebrain injury, however, only one of these studies could detect evidence of apoptosis (Park et al., 2006 and Taylor et al., 2006). It would be interesting to investigate the nature of the IGL's sensitivity to forebrain injury in light of our results.

We also demonstrate that Bim expression exhibited a similar pattern to that of NeuN in the adult brain stem and the CA3 region of the adult hippocampus (Fig. 4). Moreover, higher magnification revealed similar morphology between Bim positive and NeuN positive cells, suggesting that Bim expression in both regions was neuronal in the adult. Bim can induce programmed cell death independently of caspase activation (Liou et al., 2005); its expression in adult brain cells may therefore sensitise them to certain apoptotic stimuli. An examination of the cells that express Bim in the adult brain may provide an insight into Bim's role in the adult cerebrum, particularly in the CA3, which has been shown to be especially sensitive to brain trauma, protein hyperphosphorylation and endocrine-disruption, (Mizuhashi et al., 2000, Runden et al., 1998, Tashlykov et al., 2007).

\section{The intrinsic apoptotic pathway in the thymus}

Adult brain, muscle and heart are mainly composed of terminally differentiated cells. We wished to compare these tissues with a tissue that would still contain developing cells in early adulthood, such as the thymus, where the development of 
the T-cell repertoire continues through adolescence up to early adulthood. Bim is essential for negative selection in the thymus (Villunger et al., 2004) and caspase-3 is required for the activation-induced cell death of mature T-cells after infection (Woo et al., 1998). In contrast to brain, muscle and heart, the intrinsic apoptotic pathway proteins, Bim, Apaf-1 and caspase-3 were not down-regulated in the adult thymus (Fig. 4B). Caspase- 9 expression was similarly sustained from neonate to adulthood. Additionally, there was no apparent decrease in TUNEL positive cells in the adult thymus compared to the neonate (Fig. 4A). The presence of apoptotic cells at both ages would be attributable to the developmental processes of positive and negative selection of the developing thymocytes. While the sustained expression of key apoptotic mediators by the adult thymus is required for normal tissue function, developmental apoptosis is complete in adult brain, muscle and heart and the developmental role of these mediators is no longer be required. Furthermore, the down-regulation of said apoptotic mediators may serve to protect adult brain, heart and skeletal muscle against irreplaceable cell loss.

We showed that there is a general down-regulation of key apoptotic proteins in brain, muscle and heart. Interestingly, our immunohistochemical study revealed that key mediators of the intrinsic apoptotic pathway were not down-regulated in the IGL of the cerebellum and that individual adult brain cells expressed Bim in the brainstem and in the CA3 region of the hippocampus. There is a large body of evidence implicating apoptosis in disorders and injuries of the adult brain, heart and skeletal muscle (Mattson, 2000, Gill et al., 2002 and Tews, 2005). It is possible that the sustained global expression of caspase- 9 in brain and heart and the expression of Bim in the adult cerebrum could contribute to these traumas and disorders. There is also evidence that the down-regulated intrinsic apoptotic pathway proteins can be up-regulated in response to injury; Apaf-1 and caspase-3 are re-expressed following traumatic brain injury in the rat (Yakovlev et al., 2001) and caspase-3 is re-expressed in skeletal muscle following muscle-fibre damage (Ruest et al., 2002). Our group has also reported the apparent re-expression of caspase-3 in the ganglion cell layer of the retina in a model of glaucoma (McKernan et al., 2006). We are also currently investigating the molecular mechanisms of the developmental down-regulation of Apaf- 1 and caspase-3 in the whole retina and have described the role of histone deacetylase in the regulation of their expression during development (Wallace et al., 2006). Elucidation of the molecular mechanisms of intrinsic apoptotic protein developmental down-regulation and re-expression following disease or injury, would lead to a greater understanding of apoptosis and of the pathological conditions that effect adult tissue and may even provide therapeutic targets.

\section{Experimental Procedures}

\section{Western Blot analysis}

Tissue was harvested from Balb/c mice of random sex and was washed with cold PBS. Excised tissue was cut into pieces with scissors and homogenised in cold RIPA buffer (10mM Tris- $\mathrm{HCl} \mathrm{pH} \mathrm{7.5,150mM}$ $\mathrm{NaCl}, 1 \%$ Triton-X 100, 0.1\% SDS, $1 \mathrm{mM}$ EDTA pH 8, 0.2mM AEBSF, $1 \mathrm{X}$ protease cocktail inhibitor [Roche Diagnostics Ltd., East Sussex, United Kingdom]). Lysate total protein was determined using the Bio-
Rad protein assay (Bio-Rad, Hemel Hempstead, UK). SDS PAGE and western blot analysis were performed as standard. Anti-Apaf-1 antibody (Apotech Corporation, Epalinges, Switzerland) was used at a dilution of 1:500, anti-caspase-3 antibody and anti-caspase- 9 antibodies (Cell Signalling Technology, MA, USA) were used at dilutions of $1: 500$ and $1: 1,000$ respectively and anti-Bim antibody (Sigma, Dublin, Ireland) was used at a dilution of 1:500.

\section{$R T-P C R$}

Total RNA was isolated from excised tissue at each age using reagent according to the manufacturer's conditions (TriReagent; Molecular Research Centre, $\mathrm{OH}, \mathrm{US})$. This was then treated with DNase (Promega, WI, US) at 1 unit DNase/ $\mu \mathrm{g}$ RNA at $37^{\circ} \mathrm{C}$ for $30 \mathrm{~min}$ and subsequently reverse transcribed to CDNA using M-MLV reverse transcriptase $(2.5 \mathrm{U} / \mu \mathrm{l})$ (Promega) and $5 \mu \mathrm{M}$ random decamers (Ambion, $\mathrm{TX}, \mathrm{US})$. Products were amplified with the use of $0.05 \mathrm{U} / \mu \mathrm{L}$ polymerase ( Taq, Promega). To ensure linear signals, all products were optimized for cycle number and product amplification. Equal loading was achieved using $18 \mathrm{~S}$ rRNA as a loading control. Primers $(0.33 \mathrm{pmol} / \mu \mathrm{l})$ used were as follows:

caspase-3

forward, 5' GACTGTGGC ATTGAGACAGAC 3';

reverse, 5' TTTGCGTGGAAAGTGGAGTCC 3'; caspase-9

forward, 5' GCTTCTCTGCCACTGTACTACTGA 3';

reverse, 5' GGAAGAATTAGCCCTTCTGGTAAC 3';

$18 \mathrm{~S}$ rRNA

forward, 5' CGAGGCCCTGTAATTGGA 3';

reverse, 5' GTTTCCCGTGTTGAGTCA 3'. PCR products were separated on a $1.5 \%$ agarose gel, stained with ethidium bromide and visualized under UV light.

\section{Immunohistochemistry}

Excised tissue (also from Balb/c mice) was fixed in 10\% buffered formalin for at least 24 hours, cryo-protected by overnight incubation in $30 \%$ sucrose, embedded in tissue freezing medium (Shandon, MA, U.S.) and 5-7 $\mu \mathrm{m}$ cryo-sections were taken. Antigen was retrieved using $10 \mathrm{mM}$ Citrate $(\mathrm{pH} 6)$, after which, endogenous peroxidases were quenched in $\mathrm{H}_{2} \mathrm{O}_{2}(0.3 \%$ in $70 \%$ ethanol). The cryo-sections were then blocked in 5\% Goat Serum (Sigma) in PBS and subsequently incubated with primary antibody overnight at $4^{\circ} \mathrm{C}$. After the primary antibody was washed off, the sections were incubated with biotinylated secondary antibody (Vector Laboratories, CA, US). Antigen was detected with a stain kit and substrate (VectaStain Elite $A B C$ and DAB substrate kit; Vector Laboratories). The cryo-sections were then counterstained with Hematoxylin (Sigma) and mounted with DPX (BDH, Poole, UK). AntiApaf-1 antibody (Apotech Corporation) was used at a dilution of 1:100 and anti-caspase- 3 and anti-Bim antibodies (Cell Signalling Technology) were used at dilutions of $1: 100$ and 1:400 respectively. Antimyosin heavy chain antibody (Abcam, Cambridge, UK) was used at a dilution of 1:100, anti-NeuN antibody (Chemicon, Hampshire, UK) was used at a dilution of 1:300, anti-GFAP (DakoCytomation, Glastrup, Denmark) antibody was used at a dilution of 1:500 and anti-calbindin antibody (Sigma) was used at a dilution of 1:200. All images were taken with a Nikon DMX 1200 camera (Nikon Tokyo, Japan).

\section{TUNEL labelling}

Cryo-sections (5-7 $\mu \mathrm{m})$ were made permeable by incubation in $0.1 \%$ Triton-X/PBS for 2 min and were subsequently incubated with TUNEL reaction mixture (recombinant 0.6 unit/ $\mu$ l Terminal Deoxynucleotidyl Transferase and $1 \mathrm{X}$ reaction buffer [Promega Corporation, WI, U.S.], $3 \mu \mathrm{M}$ fluorescein-12-dUTP, [Roche Diagnostics Ltd.] and Hoechst 33342 [Sigma]) for $1 \mathrm{~h}$ at $37^{\circ} \mathrm{C}$. The cryo-sections were then washed and mounted using Mowiol (Calbiochem, WI, US). Slides were then observed using fluorescence microscopy (Leica Microsystems $\mathrm{GmbH}$, 
Wetzlar, Germany) equipped with a Nikon DMX 1200 camera (Nikon). All images were taken at $40 \mathrm{X}$ magnification.

\section{Acknowledgments}

This study was supported by the Higher Education Authority, the Health Research Board and by Science Foundation Ireland. We would like to thank Dr. Melanie Walsh for a critical reading of the manuscript and John Stockley for his helpful advice regarding brain anatomy.

\section{References}

BURGESS, D.H., SVENSSON, M., DANDREA, T., GRONLUND, K., HAMMARQUIST, F., ORRENIUS, S. and COTGREAVE, I.A. (1999). Human skeletal muscle cytosols are refractory to cytochrome c-dependent activation of type-ii caspases and lack apaf-1. Cell Death Differ. 6: 256-61.

CECCONI, F., ALVAREZ-BOLADO, G., MEYER, B.I., ROTH, K.A. and GRUSS, P. (1998). Apaf1 (ced-4 homolog) regulates programmed cell death in mammalian development. Cel/94: 727-37.

CERTO, M., DEL GAIZO MOORE, V., NISHINO, M., WEI, G., KORSMEYER, S., ARMSTRONG, S.A. and LETAI, A. (2006). Mitochondria primed by death signals determine cellular addiction to antiapoptotic bcl-2 family members. Cancer Cel/9: 351-65.

DANIAL, N.N. and KORSMEYER, S.J. (2004). Cell death: Critical control points. Cel/116: 205-19.

DEBOTTON, S., SABRI, S., DAUGAS, E., ZERMATI,Y., GUIDOTTI, J.E., HERMINE, O., KROEMER, G., VAINCHENKER, W. and DEBILI, N. (2002). Platelet formation is the consequence of caspase activation within megakaryocytes. Blood 100: 1310-7.

DONOVAN, M. and COTTER, T.G. (2002). Caspase-independent photoreceptor apoptosis in vivo and differential expression of apoptotic protease activating factor-1 and caspase-3 during retinal development. Cel/ Death Differ. 9: 122031.

DONOVAN, M., DOONAN, F. and COTTER, T.G. (2006). Decreased expression of pro-apoptotic bcl-2 family members during retinal development and differential sensitivity to cell death. Dev. Biol. 291: 154-69.

FERNANDO, P., KELLY, J.F., BALAZSI, K., SLACK, R.S. and MEGENEY, L.A. (2002). Caspase 3 activity is required for skeletal muscle differentiation. Proc. Natl. Acad. Sci. U S A 99: 11025-30.

FUENTES-PRIOR, P. and SALVESEN, G.S. (2004). The protein structures that shape caspase activity, specificity, activation and inhibition. Biochem. J. 384: 201-32.

GILL, C., MESTRIL, R. and SAMALI, A. (2002). Losing heart: The role of apoptosis in heart disease-a novel therapeutic target? Faseb. J. 16: 135-46.

HAKEM, R., HAKEM, A., DUNCAN, G.S., HENDERSON, J.T., WOO, M., SOENGAS, M.S., ELIA, A., DE LA POMPA, J.L., KAGI, D., KHOO, W. et al. (1998). Differential requirement for caspase 9 in apoptotic pathways in vivo. Cel/94: 339-52.

KUIDA, K., ZHENG, T.S., NA, S., KUAN, C., YANG, D., KARASUYAMA, H., RAKIC, P. and FLAVELL, R.A. (1996). Decreased apoptosis in the brain and premature lethality in cpp32-deficient mice. Nature 384: 368-72.

KUIDA, K., HAYDAR, T.F., KUAN, C.Y., GU, Y., TAYA, C., KARASUYAMA, H., SU, M.S., RAKIC, P. and FLAVELL, R.A. (1998). Reduced apoptosis and cytochrome c-mediated caspase activation in mice lacking caspase 9. Cel/94: 32537.

LIOU, A.K., ZHOU, Z., PEI, W., LIM, T.M., YIN, X.M. and CHEN, J. (2005). Bimel up-regulation potentiates aif translocation and cell death in response to mptp. Faseb. J. 19: 1350-2.

MANDAL, M., ADAM, L. and KUMAR, R. (1999). Redistribution of activated caspase-3 to the nucleus during butyric acid-induced apoptosis. Biochem. Biophys. Res. Commun. 260: 775-80.

MATTSON, M.P. (2000). Apoptosis in neurodegenerative disorders. Nat. Rev. Mol. Cell Biol. 1: 120-9.

MCKERNAN, D.P., CAPLIS, C., DONOVAN, M., O'BRIEN C, J. and COTTER, T.G.
(2006). Age-dependent susceptibility of the retinal ganglion cell layer to cell death. Invest. Ophthalmol. Vis. Sci. 47: 807-14.

MIZUHASHI, S., IKEGAYA, Y. and MATSUKI, N. (2000). Cytotoxicity of tributyltin in rat hippocampal slice cultures. Neurosci. Res. 38: 35-42.

MORISHIMA, N., NAKANISHI, K., TAKENOUCHI, H., SHIBATA, T. and YASUHIKO, Y. (2002). An endoplasmic reticulum stress-specific caspase cascade in apoptosis. Cytochrome c-independent activation of caspase-9 by caspase-12. J. Biol. Chem. 277: 34287-94.

MULLEN, R.J., BUCK, C.R. and SMITH, A.M. (1992). NeuN, a neuronal specific nuclear protein in vertebrates. Development 116: 201-11.

NOYAN-ASHRAF, M.H., BRANDIZZI, F. and JUURLINK, B.H. (2005). Constitutive nuclear localization of activated caspase 3 in subpopulations of the astroglial family of cells. Glia 49: 588-93.

PARK, E., MCKNIGHT, S., AI, J. and BAKER, A.J. (2006). Purkinje cell vulnerability to mild and severe forebrain head trauma. JNeuropathol. Exp. Neurol. 65: 22634.

RAMUZ, O., ISNARDON, D., DEVILARD, E., CHARAFE-JAUFFRET, E., HASSOUN, J., BIRG, F. and XERRI, L. (2003). Constitutive nuclear localization and initial cytoplasmic apoptotic activation of endogenous caspase-3 evidenced by confocal microscopy. Int. J. Exp. Pathol. 84: 75-81.

RAO, R.V., HERMEL, E., CASTRO-OBREGON, S., DEL RIO, G., ELLERBY, L.M., ELLERBY, H.M. and BREDESEN, D.E. (2001). Coupling endoplasmic reticulum stress to the cell death program. Mechanism of caspase activation. J. Biol. Chem. 276: 33869-74.

RIEDL, S.J. and SHI, Y. (2004). Molecular mechanisms of caspase regulation during apoptosis. Nat. Rev. Mol. Cell Biol. 5: 897-907.

RUEST, L.B., KHALYFA, A. and WANG, E. (2002). Development-dependent disappearance of caspase-3 in skeletal muscle is post-transcriptionally regulated. J. Cell Biochem. 86: 21-8.

RUNDEN, E., SEGLEN, P.O., HAUG, F.M., OTTERSEN, O.P., WIELOCH, T., SHAMLOO, M. and LAAKE, J.H. (1998). Regional selective neuronal degeneration after protein phosphatase inhibition in hippocampal slice cultures: evidence for a MAP kinase-dependent mechanism. J. Neurosci. 18: 7296-305.

SLEE, E.A., ADRAIN, C. and MARTIN, S.J. (2001). Executioner caspase-3, -6 and -7 perform distinct, non-redundant roles during the demolition phase of apoptosis. J. Biol. Chem. 276: 7320-6.

SORDET, O., ReBe, C., PLENCHETTE, S., ZeRMATI, Y., HeRMine, O., VAINCHENKER, W., GARRIDO, C., SOLARY, E. and DUBREZ-DALOZ, L. (2002). Specific involvement of caspases in the differentiation of monocytes into macrophages. Blood 100: 4446-53.

STOKA, V., TURK, V. and BREDESEN, D.E. (2006). Differential regulation of the intrinsic pathway of apoptosis in brain and liver during ageing. FEBS Lett. 580 : 3739-45.

TASHLYKOV, V., KATZ, Y., GAZIT, V., ZOHAR, O., SCHREIBER, S. and PICK, C.G. (2007). Apoptotic changes in the cortex and hippocampus following minimal brain trauma in mice. Brain Res. 1130: 197-205.

TAYLOR, D.L., JOASHI, U.C., SARRAF, C., EDWARDS, A.D. and MEHMET, H. (2006). Consequential apoptosis in the cerebellum following injury to the developing rat forebrain. Brain Pathol. 16: 195-201.

TEWS, D.S. (2005). Muscle-fiber apoptosis in neuromuscular diseases. Muscle Nerve 32: 443-58.

VILLUNGER, A., MARSDEN, V.S., ZHAN, Y., ERLACHER, M., LEW, A.M., BOUILLET, P., BERZINS, S., GODFREY, D.I., HEATH, W.R. and SRASSER, A. (2004) Negative selection of semimature cd4(+)8(-)has+ thymocytes requires the bh3-only protein bim but is independent of death receptor signalling Proc. Natl. Acad. Sci. US A 101:7052-7.

WALLACE, D.M., DONOVAN, M. and COTTER, T.G. (2006). Histone deacetylase activity regulates apaf-1 and caspase 3 expression in the developing mouse retina. Invest. Ophthalmol. Vis. Sci. 47: 2765-72.

WOO, M., HAKEM, R., SOENGAS, M.S., DUNCAN, G.S., SHAHINIAN, A., KAGI D., HAKEM, A., MCCURRACH, M., KHOO, W., KAUFMAN, S.A. et al. (1998). Essential contribution of caspase $3 / \mathrm{CPP} 32$ to apoptosis and its associated nuclear changes. Genes Dev. 12: 806-19.

XU, C., BAILLY-MAITRE, B. and REED, J.C. (2005). Endoplasmic reticulum stress: 
Cell life and death decisions. J Clin. Invest. 115: 2656-64

YAKOVLEV, A.G., OTA, K., WANG, G., MOVSESYAN, V., BAO, W.L., YOSHIHARA, K. and FADEN, A.I. (2001). Differential expression of apoptotic proteaseactivating factor- 1 and caspase- 3 genes and susceptibility to apoptosis during brain development and after traumatic brain injury. J. Neurosci. 21: 7439-46.

YOSHIDA, H., KONG, Y.Y., YOSHIDA, R., ELIA, A.J., HAKEM, A., HAKEM, R., PENNINGER, J.M. and MAK, T.W. (1998). Apaf1 is required for mitochondrial pathways of apoptosis and brain development. Cel/94: 739-50.
ZERMATI, Y., GARRIDO, C., AMSELLEM, S., FISHELSON, S., BOUSCARY, D., VALENSI, F., VARET, B., SOLARY, E. and HERMINE, O. (2001). Caspase activation is required for terminal erythroid differentiation. J. Exp. Med. 193: 247-54.

Received: 18th December 2006

Reviewed by Referees: 19th February 2007

Modified by Authors and Accepted for Publication: 2nd May 2007

Published Online: 25th June 2007

\section{Related, previously published Int. J. Dev. Biol. articles}

See our recent Special Issue on Invasion in Cancer \& Embryonic Development edited by Marc Mareel and Juan Aréchaga at: http://www.ijdb.ehu.es/web/contents. php?vol=48\&issue=5-6

Stage-specific regulation of programmed cell death during oogenesis of the medfly Ceratitis capitata (Diptera, Tephritidae)

Athanassios D. Velentzas, loannis P. Nezis, Dimitrios J. Stravopodis, Issidora S. Papassideri and Lukas H. Margaritis Int. J. Dev. Biol. (2007) 51: 57-66

Isolation of apoptotic mouse fetal oocytes by AnnexinV assay

Anna-Maria Lobascio, Francesca-Gioia Klinger and Massimo De Felici

Int. J. Dev. Biol. (2007) 51: 157-160

NMDA-receptor blockade enhances cell apoptosis in the developing retina of the postnatal rat María Hernández, Inmaculada Guerrikagoitia, Luis Martínez-Millan and Elena Vecino Int. J. Dev. Biol. (2007) 51: 117-122

Proliferation and apoptosis in early molar morphogenesis - voles as models in odontogenesis Jana Setkova, Herve Lesot, Eva Matalova, Kirsti Witter, Petra Matulova and Ivan Misek Int. J. Dev. Biol. (2006) 50: 481-489

Retinal ganglion cells: dying to survive

Marc B. Guerin, Declan P. McKernan, Colm J. O'Brien and Thomas G. Cotter Int. J. Dev. Biol. (2006) 50: 665-674

Molar tooth development in caspase-3 deficient mice

Eva Matalova, Paul T. Sharpe, Saquib A. Lakhani, Kevin A. Roth, Richard A. Flavell, Jana Setkova, Ivan Misek and Abigail S. Tucker

Int. J. Dev. Biol. (2006) 50: 491-497

Metamorphosis of Hydractinia echinata (Cnidaria) is caspase-dependent Stefanie Seipp, Karola Wittig, Beate Stiening, Angelika Böttger and Thomas Leitz Int. J. Dev. Biol. (2006) 50: 63-70

A generalized caspase inhibitor disrupts early mammalian development Zahra Zakeri Richard A. Lockshin, Luis-Miguel Criado-Rodríguez and Carlos Martínez-A Int. J. Dev. Biol. (2005) 49: 43-51

PVF1/PVR signaling and apoptosis promotes the rotation and dorsal closure of the Drosophila male terminalia Ana Macías, Nuria M. Romero, Francisco Martín, Leonardo Suárez, Alberto L. Rosa and Ginés Morata Int. J. Dev. Biol. (2004) 48: 1087-1094

Blind cavefish and heat shock protein chaperones: a novel role for hsp90alpha in lens apoptosis Thomas A. Hooven, Yoshiyuki Yamamoto and William R. Jeffery

Int. J. Dev. Biol. (2004) 48: 731-738

Programmed cell death is not a necessary prerequisite for fusion of the fetal mouse palate. Sachiko Takahara, Toshiya Takigawa and Kohei Shiota Int. J. Dev. Biol. (2004) 48: 39-46

Inhibition of apoptosis in the primary enamel knot does not affect specific tooth crown morphogenesis in the mouse.

$R$ Coin, S Kieffer, H Lesot, J L Vonesch and J V Ruch

Int. J. Dev. Biol. (2000) 44: 389-396 


\section{EYE DEVELOPMENT}

\section{Edited by foram Piatigorsky and Robert M. Grainger}

Preface

by Joram Piatigorsky and Robert M. Grainger

\section{PERSONAL VIEWS}

The extracellular matrix in development and regeneration. An interview with

Elizabeth D. H ay

by Robert L. T relstad

A life in research on lens regeneration and transdifferentiation. An interview with

Goro Eguchi

by Kunio Yasuda

\section{DEVELOPMENTAL EVOLUTION OF VISUAL ORGANS}

Evolving eyes

by Russell D. Fernald

$H$ istorical perspective on the development and evolution of eyes and

photoreceptors

by Walter J. Gehring

Cubozoan jellyfish: an Evo/ Devo model for eyes and other sensory systems

by Joram Piatigorsky and Zbynek K ozmik

Blind cavefish and heat shock protein chaperones: a novel role for hsp $90 \alpha$ in lens apoptosis

by Thomas A. H ooven, Yoshiyuki Yamamoto and William R. Jeffery

\section{EMBRYONIC INDUCTION AND EYE SPECIFICATION}

From embryonic induction to cell lineages: revisiting old problems for modern study

by Tokindo S. Okada

Conservation and non-conservation of genetic pathways in eye specification

by Amy L. Donner and Richard L. M aas

The little $R$ cell that could

by Raghavendra Nagaraj and Utpal Banerje

Regulation of vertebrate eye development by $R \times$ genes

by Travis J. Bailey, H eithem El-hodiri, Li Zhang,

Rina Shah, Peter H. M athers and M ilan Jamrich

A re-examination of lens induction in chicken embryos: in vitro studies of early tissue interactions

by Charles H. Sullivan, Leslie Braunstein, Royce M. H azard-L eonards, Anna L.

$\mathrm{H}$ olen, Fouad Samaha, Laurie Stephens and R obert M . Grainger

Pathways regulating lens induction in the mouse

by Richard A. L ang

Analysis of mouse eye development with chimeras and mosaics

by J. M artin Collinson, Robert E. H ill and John D. West

\section{LENS \& CORNEA DEVELOPMENT}

Lens differentiation and crystallin regulation: a chick model

by $\mathrm{H}$ asan M. Reza and Kunio Yasuda

Interplay of Pax6 and SOX2 in lens development as a paradigm of genetic switch mechanisms

for cell differentiation

by $\mathrm{H}$ isato $\mathrm{K}$ on doh, M asanori Uchikawa and Yusuke Kamachi

Regulation of gene expression by Pax6 in ocular cells: a case of tissue-preferred expression of crystallins in lens

by Ales Cvekl, Ying Yang, Bharesh K. Chauhan and Kveta Cveklova

Contributions by members of the T G Fbeta superfamily to lens development

by David Beebe, Claudia Garcia, Xiaohui Wang, Ramya Rajagopal, M ary Feldmeier, Ji Y

Kim, Anna Chytil, H arold M oses, Ruth A shery-Padan, and M ichael Rauchman

Regulation of cell adhesion and migration in lens development

by Peggy S. Zelenka

Expression of Frizzleds and secreted frizzled-related proteins (Sfrps) during mammalian lens development

by Yongjuan Chen, Richard J.W. Stump, Frank J. Lovicu and John W. M cavoy

Activated Ras induces lens epithelial cell hyperplasia but not premature

differentiation

by Lixing W. Reneker, LeikeXie, Li Xu, Venkatesh Govindarajan and Paul A. Overbed

Development of lens sutures

by Jer R. Ku uszak, Rebecca K. Zoltoski and Clifford E. Tiedemann
"Seeing is what matters. Seeing must suffice." René Magritte (1898-1967, Belgium). In this 1935 version of the surrealist LeFauxMiroir (The False Mirror) first painted by René Magritte in 1928, the inverted iris/pupil acts as a mirror of the exterior world instead of being the mirror of the soul. In his art, Magritte used the unexpected to liberate our con-ventional vision from its obscurity, in order to glimpse the hidden mystery of the visible world. As Magritte says "Everything we see hides another thing."

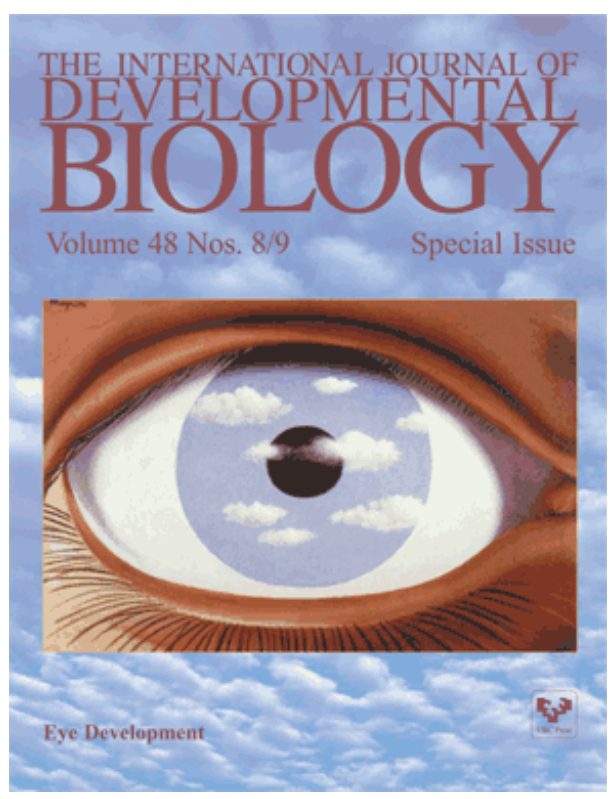

Corneal development associated with eyelid opening

by James D. Zieske

\section{RETINA DIFFERENTIATION}

G enetic control of retinal specification and determination in Drosophila by Kartik S. Pappu and Graeme M ardon

Genetics of photoreceptor development and function in zebrafish

by M otokazu T sujikawa and Jarema M alicki

A moving wave patterns the cone photoreceptor mosaic array in the zebrafish retina by Pamela A. Raymond and Linda K. Barthe

Neurotrophic regulation of retinal ganglion cell synaptic connectivity: from axons and dendrites to synapses

by Susana Cohen-Cory and Barbara Lom

New views on retinal axon development: a navigation guide

by Fanny M ann. William A. H arris and Christine E. H olt

Cell death in the developing vertebrate retina

by Elena Vecino, M aría H ernández and M ónica García

\section{O CULAR STEM CELLS AND REGENERATION}

$A$ newt's eye view of lens regeneration

by Panagiotis A. T sonis, M ayur M adhavan, Emily T ancous and Katia Del Rio-T sonis

O cular surface epithelial and stem cell development

by J. M ario Wolosin, M urat T. Budak and M .A.M urat A kinci

Retinal stem cells in vertebrates: parallels and divergences

by $\mathrm{M} \operatorname{arcos} \mathrm{A}$. A mato, Emilie Arnault and $\mathrm{M}$ uriel Perron

Retinal stem cells and regeneration

by Ala M oshiri, JennieClose and Thomas A. Reh

\section{BIOPATHOLOGY OF EYE DEVELOPMENT}

Anterior segment development relevant to glaucoma

by Douglas B. Gould, Richard S. Smith and Simon W.M. John

Congenital hereditary cataracts

by Jochen Graw

Development and pathology of the hyaloid, choroidal and retinal vasculature

by M agali Saint-Geniez and Patricia A. D'amore

\section{ORDER FORM}

I would like to order cop(y/ies) of the Int. J. Dev. Biol. Special Issue “Eye Development” (Vol. 48, Nos. 8/9) at US\$ 90 or Euro €70 per copy (including post and packaging). Total to be charged: US\$ / Euro $€$ (please specify currency)

\section{ORDER BY}

$\checkmark$ Web:

http://www.intjdevbiol.com/purchase.htm

$\checkmark$ E-mail: ijdb@ehu.es (include the information indicated above)

$\checkmark$ FAX: +34-94-601-3266

$\checkmark$ POST: to the address shown to the right
The International Journal of Developmental Biology

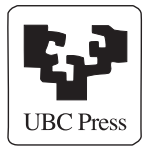

Editorial Office, Uni. of the Basque Country

Dept. Cell Biology and Histology Faculty of Medicine, E-48940 Leioa

Vizcaya, SPAIN 